\title{
Analysis of dog fat in beef sausage using FTIR (Fourier Transform Infrared) combined with chemometrics
}

\author{
Any Guntarti*, Zelinda Ayu Purbowati \\ Faculty of Pharmacy, Universitas Ahmad Dahlan \\ Jl.Prof. Dr. Soepomo S.H, Janturan, Yogyakarta
}

\begin{abstract}
Sausage is ready to eat meals for children and adults. The meat contained in a beef sausage might not be consistent to the one listed on the label. FTIR (Fourier Transform Infrared) spectroscopy combined with a chemometric method was the most used methods to detect beef fat with rapid and consistent results. Results of analysis can classify fatty acid composition. The aim of this study was to know the profile of spectra and grouping of beef tallow and dog meat with FTIR. The study was designed by making 7 different variations of dog reference sample concentrations $(100 \%, 75 \%, 65 \%$, $50 \%, 35 \%, 25 \%$, and $100 \%$ ) beef fat and five other samples were gathered from various street vendors. Results were analyzed using FTIR spectroscopy combined with chemometric with PLS (Partial Least Square) and PCA (Principal Component Analysis). The results of analysis will be analysed using Horizon MB application to obtained optimal wave number at $688-1124 \mathrm{~cm}^{-1}$. Results equation obtained $\mathrm{y}=0.9999 \mathrm{x}+0.0004$ and value $\mathrm{R}^{2}$ equal to 0.9999; RMSEC (root mean square error of calibration) of $0.30 \%$; RMSEP (root mean square error of prediction) of $0.05 \%$ and RMSECV (root mean square error of cross validation) of $0.05 \%$. The low values of RMSEP, RMSEC, RMSECV and $\mathrm{R}^{2}$ close to one indicate that the FTIR combined with chemometric is an appropriate method for analyzing the presence of fat content in the sample. From the analysis showed that 1 of 5 sausage market samples has similarities with dog fat.
\end{abstract}

Keywords: beef fat, dog fat, sausage, FTIR, chemometric

*Corresponding author:

Any Guntarti

Faculty of Pharmacy, Universitas Ahmad Dahlan

Jl.Prof. Dr. Soepomo S.H, Janturan, Yogyakarta

Email: any_guntarti@yahoo.co.id 


\section{INTRODUCTION}

Food is a basic necessity for human beings, so the availability of food need serious attention in quality \& quantity. Foodstuffs can be derived from crops or livestock. Livestock products are the main source of nutrition for growth and human life (Gustiani, 2009). One of the livestock products containing high nutritional value are meat. With increasing people's income caused the demand for consumption of meat in some areas of Indonesia are increasing (Syahariza et al., 2005). Increased consumption of meat in Indonesia not only include halal meat but also non halal meat, like in some regions local food (Rafi et al., 2016). It can be seen from the large number of processed dog meat sellers and dogs provided each week for slain.

The current counterfeiting halal meat using a dog meat quite profitable since the trade of wild dogs in several countries is done at low prices. "Pikiran Rakyat" in December 2016 mentions the discovery of counterfeit products of beef using a dog meat in Bandung Raya (Sukirman, 2016). In addition to food safety, the halal food products are a factors that should also be a concern. Current awareness of muslim societies to consume halal food increased along with public awareness of Islamic laws (Che Man et al., 2005; Mursyidi, 2013; Rohman et al., 2014). Thus, it is necessary to know the laboratory testing posed the possibility of forgery meat precisely and accurately.

Laboratory testing for the presence of counterfeit used FTIR combined with chemometric (Jaswir et al., 2003; Rohman et al., 2012; Guntarti et al., 2015). The advantages of this method are simple, non destructive, sensitive, little sample needed, and does not involve the preparation of complex samples (Ronggo et al., 2007; Rahul et al., 2012). Data processing combined with chemometric to obtain important information about a particular object on the data using mathematical or statistical techniques. Types of chemometrics that most commonly used are (1) grouping techniques, such as Principal Component Analysis (PCA) and (2) quantitative analysis with multivariate calibration, such as Partial Least Square (PLS) (Miller and Miller, 2005).

This research aims to know the profile of spectra and grouping of beef tallow and dog meat with FTIR. In addition to knowing whether or not there are impurities in the processed beef sausage that is on the market. The results of this research can be used as preliminary research to find out the content of non-halal food products.

\section{MATERIALS AND METHOD}

\section{Tools and materials}

The materials used in this research was fat from beef and dog sausage, $n$-hexane, anhydrous $\mathrm{Na}_{2} \mathrm{SO}_{4}$ and sausage sample market (Munawaroh and Prima, 2010). FTIR spectrophotometer instrument $3000 \mathrm{MB}$ ABB (Canada) equipped with ZnSe Crystal plate, deuterated detector triglycine sulfate (DTGS) sample handling techniques with attenuated total reflectance (ATR), as well as x-ray beam splitter in Germanium $\mathrm{KBr}$ substrate. Droplet of oil placed on the ATR crystal controlled temperature $\left(20^{\circ} \mathrm{C}\right)$. The measurement was done at $32 \mathrm{scan}$, separating power (resolution) $4 \mathrm{~cm}^{-1}$, glass tools, Soxhlet (Guntarti et al., 2015).

\section{Research Prosedure}

Meat Supply

Dog meat was obtained from Kasongan, Bantul, Yogyakarta and beef meat from market. Aside from that, sausage products were also obtained from street vendors and traditional markets in Yogyakarta.

\section{Sausage production}

Grounded beef was measured according to the formula, and then it was mashed with a blender. After that, excipient was added, including flour, garlic, and eggs. 


\section{Fat extraction}

Beef and dog meat were measured according to the formulation, and then chopped and mashed, then strained and put in Soxhlet. Solvent $n$-hexane was added twice. Extraction using Soxhlet was done for 5-7 hours and the temperature was maintained in $70^{\circ} \mathrm{C}$. The finished results were fat containing n-hexane solution. Then, $\mathrm{Na}_{2} \mathrm{SO}_{4}$ anhydrate was added and filtered using strain paper. Obtained fat was moved into effendorf to be further analyzed with FTIR (Guntarti et al., 2015).

\section{Data Analysis}

Results of FTIR spectrum then analyzed using chemometric program with HorizonMB software, Microsoft Word and Microsoft Excel 2007. The samples were analyzed at $4000 \mathrm{~cm}^{-1}$ to 650 $\mathrm{cm}^{-1}$ wavenumbers. Multivariate analysis including calibration with PLS and PCA performed with HorizonMB program.

\section{RESULTS AND DISCUSSION \\ Extraction of Fat}

Extraction of fat by Soxhlet based on solid-liquid extraction. It used n-hexane solvent because its more stable, rigid, has a non-polar solubility, low boiling point, and low price (Munawaroh, 2010). It difference in organoleptic between dog and beef fat in colour and odour shown are sausage (Table I).

Table I. Identification of the type of beef and dog fat in sausages samples

\begin{tabular}{llll}
\hline Type Fat & $\begin{array}{l}\text { Consistency at Room } \\
\text { temperature }\end{array}$ & Colour Fat & Fatty Odour \\
\hline Beef & Solid & Yellow & Not odorless \\
Dogs & Liquid & White & Typical smell \\
\hline
\end{tabular}

Based on the Table I, the differences can be seen between beef and dog fat in sausage. The beef fat in sausage has the consistency of a solid at room temperature, while the dog fat in sausage has a liquid consistency at room temperature. The difference in consistency on both types of fat content due to the constituent fatty acids on dog fat has many double bonds. The more number of double bonds in fatty acids, then the lower its melting point (Kusnandar, 2010).

\section{Identification of the functional groups of beef and dog fat in sausages}

Infrared spectrum analysis is unique, thus it's usually called fingerprint analysis. Different kind of substance will create different intensity, peak value, or wave number of extract for every peak. The reading of IR spectrum was done by mid-wave number, which was $4000-650 \mathrm{~cm}^{-1}$. Mid-wave number was chosen because it can give sufficient information of the functional groups within the lipid. The difference between Beef Fat Spectrum (BS) and Dog Fat Spectrum (DS) at 100\% are shown in Figure 1. 


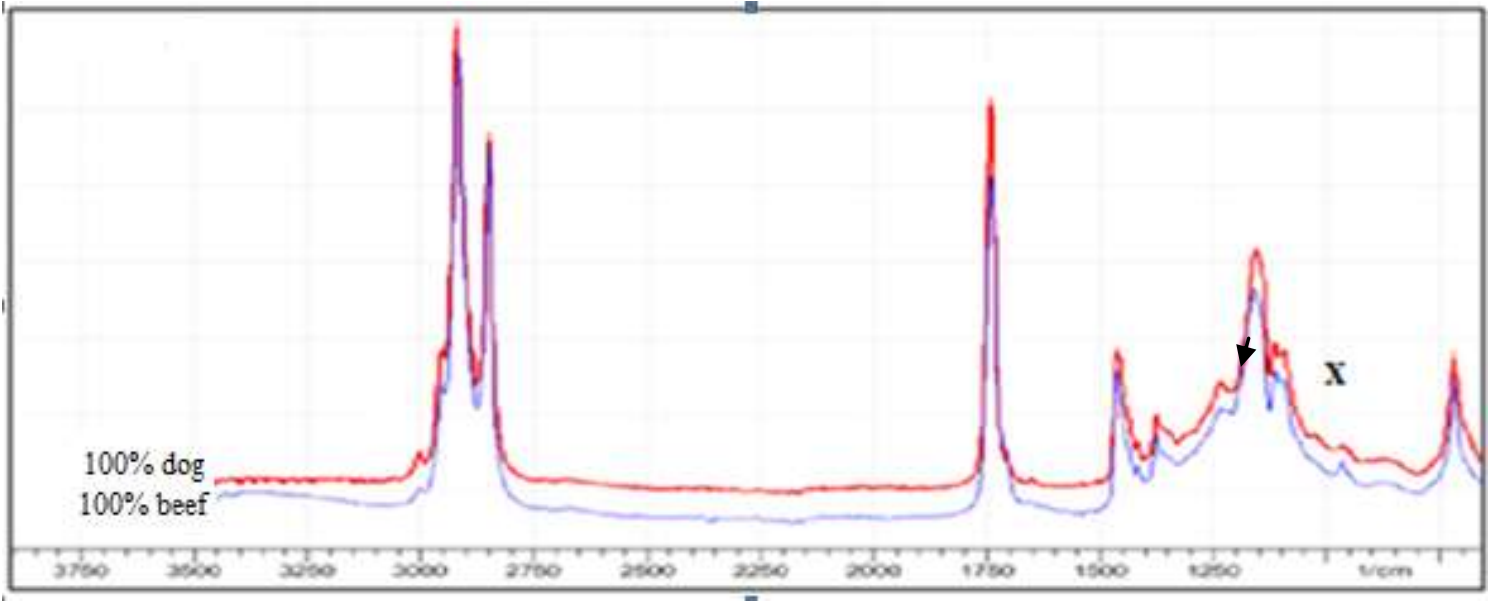

Figure 1. The difference between Beef Fat Spectrum (BS) and Dog Fat Spectrum (DS) at 100\%

At a glance there's no significant difference between the spectra of fatty BS and spectra of DS. There was stretching $\mathrm{CH}$ double bond in the $3006 \mathrm{~cm}^{-1}$. The existence of vibration of the Cis $-\mathrm{C}=$ $\mathrm{CH}$ on the numbers on the spectra and DS identifies the presence of unsaturated fatty acids on fat. On the wave number $1743 \mathrm{~cm}^{-1}$ there was a peak which indicates the carbonyl group $(\mathrm{C}=\mathrm{O})$ on the $\mathrm{BS}$ and the DS. Both of these fats may occur because the basic structure of fat triacylglycerols that contains 3 pieces of the carbonyl group of the esther. The peaks at wave number $1097 \mathrm{~cm}^{-1}$ slower output of the $\mathrm{C}-\mathrm{O}$ from the cluster of esther.

The typical fat in beef and dog was in wave number $1031 \mathrm{~cm}^{-1}$, peak (x) was only found in the dog fat whereas in beef fat not contained. On the wave number $1157 \mathrm{~cm}^{-1}$ there was vibration buckling of $-\mathrm{CH}$ in those wave numbers on plane. On the wave number $2921 \mathrm{~cm}^{-1}$ on both fat there are vibrations of asymmetric and symmetric methylene $\left(-\mathrm{CH}_{3}\right)$. There was no significant difference between spectra BS and DS. The analysis of functional group of Beef Fat Spectrum and Dog Fat Spectrum as well as IR vibration are shown in Table II.

Table II. The analysis of functional group of beef fat spectrum and dog fat spectrum as well as IR vibration

\begin{tabular}{|c|c|c|}
\hline $\begin{array}{l}\text { Wave number } \\
\left(\mathrm{cm}^{-1}\right)\end{array}$ & Functional Group Vibration & Intensity \\
\hline 3004 and 3006 & Cis $\mathrm{C}=\mathrm{CH}$ stretching & Weak \\
\hline 2955 & $\begin{array}{l}\text { Asymetric stretching vibration of methylen group (- } \\
\left.\mathrm{CH}_{2}\right)\end{array}$ & Medium \\
\hline 2919 and 2920 & $\begin{array}{l}\text { Asymetric and symetric stretching vibration of } \\
\text { methylen group }\left(-\mathrm{CH}_{2}\right)\end{array}$ & Strong \\
\hline 1742 and 1743 & $\begin{array}{l}\text { Functional carbonyl group }(\mathrm{C}=\mathrm{O}) \text { of triacylglycerol } \\
\text { esther bond }\end{array}$ & Strong \\
\hline 1377 & Symetric bending vibration of methylen group $\left(-\mathrm{CH}_{2}\right)$ & Medium \\
\hline 1235 & Stretching vibration of $\mathrm{C}-\mathrm{O}$ group in esther & Medium \\
\hline 1158 and 1161 & Bendring vibration of $-\mathrm{CH}$ in plane group & Strong \\
\hline 1097 and 1098 & Stretching vibration of $\mathrm{C}-\mathrm{O}$ from esther bond & Medium \\
\hline 964 and 965 & $\begin{array}{l}\text { Bending vibration of } \mathrm{CH} \text { functional group of isolated } \\
\text { trans-olefin }\end{array}$ & Medium \\
\hline 720 and 721 & $\begin{array}{l}\text { Overlapping vibration of methylen }\left(-\mathrm{CH}_{2}\right) \text { and out of } \\
\text { plane vibration by cis-distribution }\end{array}$ & Medium \\
\hline
\end{tabular}

Pharmaciana Vol. 9, No. 1, May 2019, Page. $21-28$ 


\section{Quantitative Analysis using PLS}

Partial Least Square (PLS) was used as a quantitative analysis of beef fat and dog fat in the preparation of sausages. FTIR spectrum of Beef Fat Spectrum and Dog Fat Spectrum in gradual concentration in the middle infrared area $\left(4000-650 \mathrm{~cm}^{-1}\right)$ are shown in Figure 2. Results showed in wavenumber optimization in area 1124-688 $\mathrm{cm}^{-1}$. This wavenumber has an unique functional group of dogs meat 1124-688 $\mathrm{cm}^{-1}$. Aside the wave numbers, there is a significant difference between the BS and DS. This is in accordance with Ratnasari (2016), which states that the number of areas that demonstrate the specificity of dog fat in the wave number $1123 \mathrm{~cm}^{-1}$. The results of optimization showed that wave number $1124-688 \mathrm{~cm}^{-1}$ generated value $\mathrm{R}^{2}=0,9999$ and RMSEC $=0,30 \%$. The results amounted to $0.05 \%$ RMSEP and RMSECV value of $0.05 \%$. The value of RMSECV and RMSEP were validation parameters.

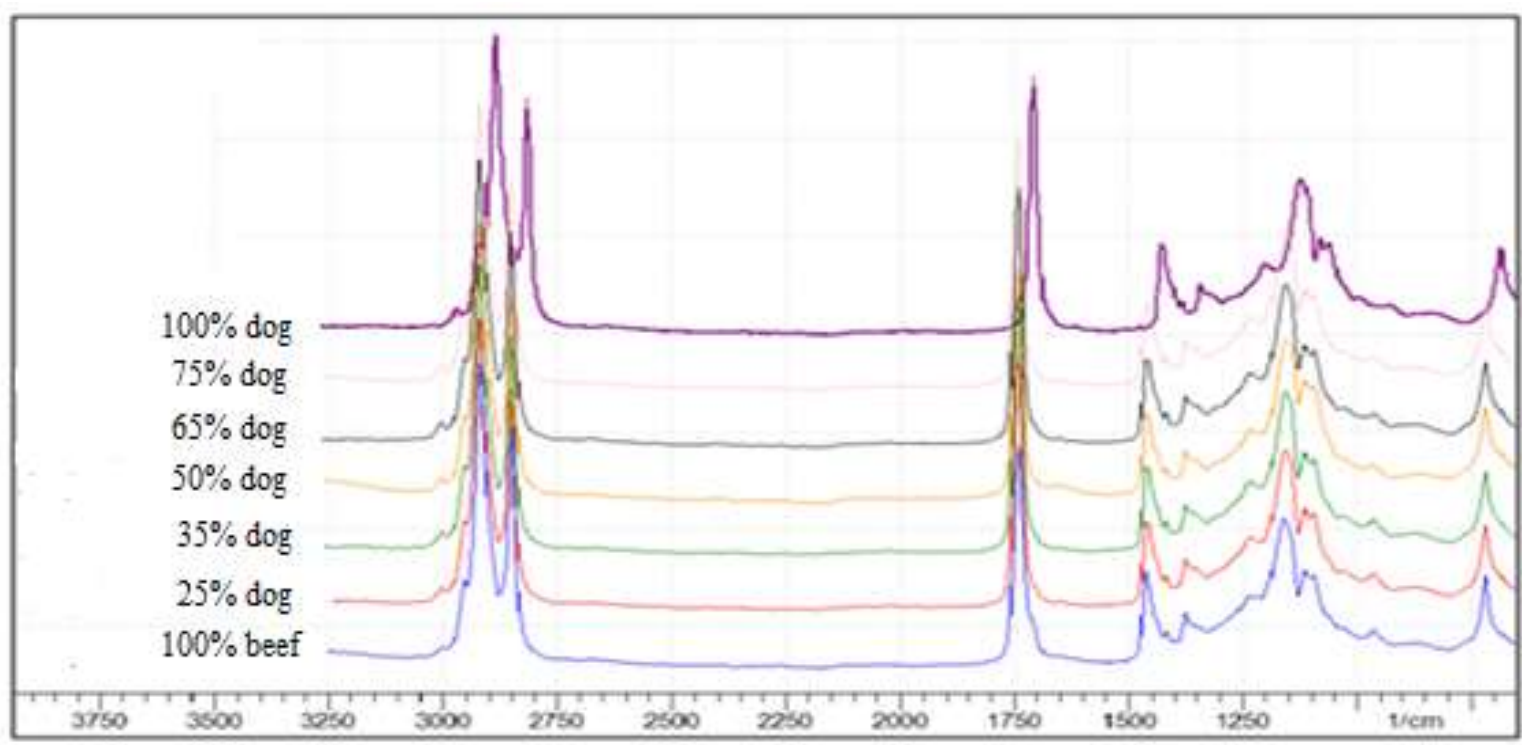

Figure 2. FTIR spectrum of beef fat spectrum and dog fat spectrum in gradual concentration in the middle infrared area $\left(4000-650 \mathrm{~cm}^{-1}\right)$

\section{Classification of Fatty Acid using PCA}

Principal Component Analysis (PCA) was a data interpretation method that done by data prediction. The amount of variable in a matrix was reduced to generate a new variable by maintaining the information of the data. The new variable was in the form of scores or main component. This technique can decrease the effect of noise and utilize the slight differences of IR spectrum. To analyze PCA, Beef Fat Spectrum 100\% samples and Dog Fat Spectrum 100\% samples from sausage extraction were used. PCA chemometric can be used to classified beef and dog lipid (Miller and Miller, 2005). In this research, it can be known that both samples was located on a different quadrant. Where the distance between the plot shows the similarities between the fat. It can be seen that the distance between the dog and beef fat separate long (Figure 3). 


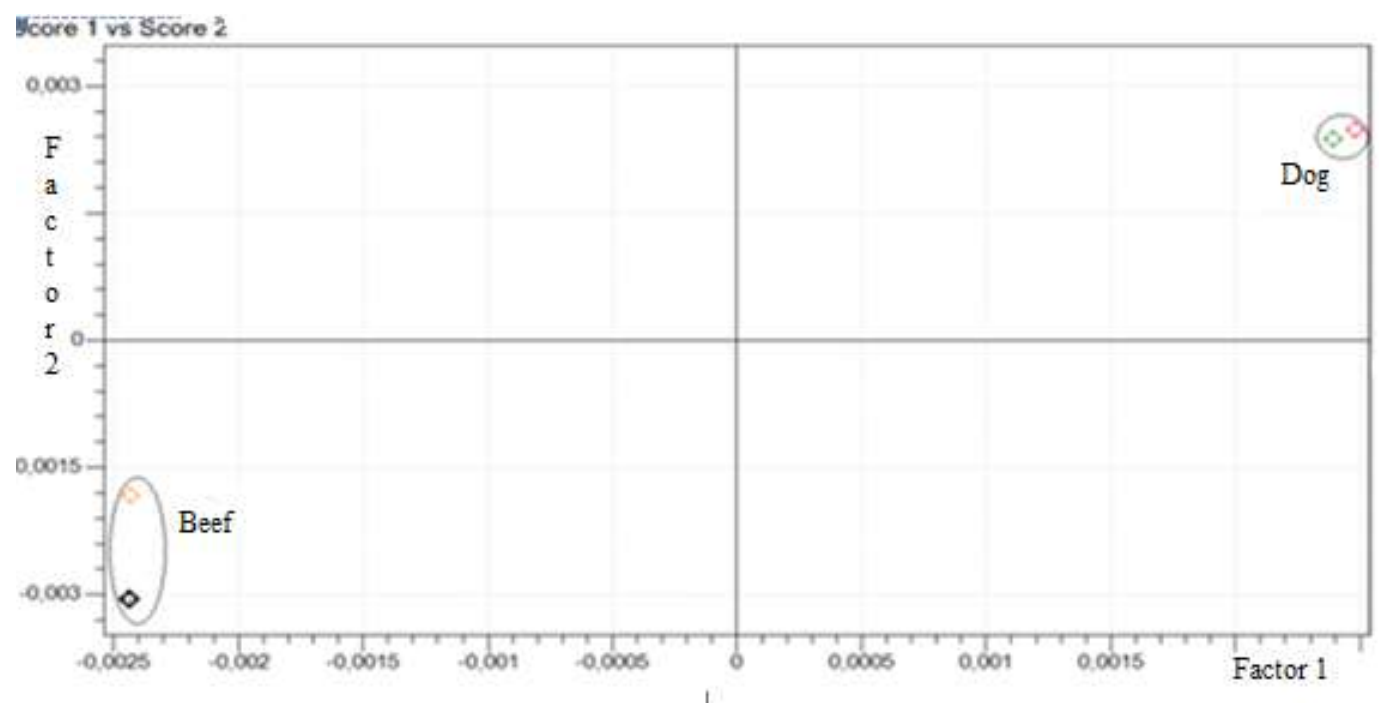

Figure 3. Graphic of score plot of beef and dog fat in sausages

\section{Analysis of sausage products circulating in the market}

Sausage samples in the general market was obtained from traditional market vendors. Spectrum was measured in an optimized wavenumber, which was $1124-688 \mathrm{~cm}^{-1}$. The results of PCA analysis in a Score Plot are shown in Figure 4.

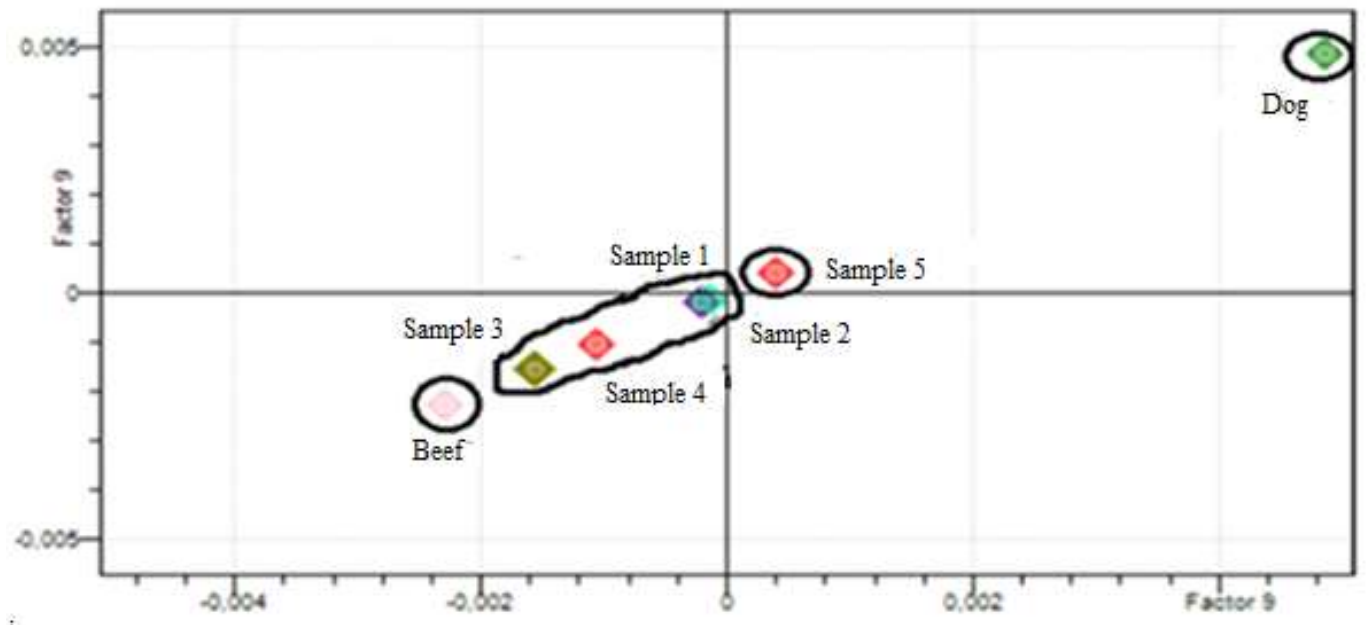

Figure 4. The results of PCA analysis in a Score Plot

In Figure 4, sample 1, 2, 3 and 4 adjacent to the beef fat. The closer the distance of score sample plots then the greater the likelihood that the sample contains pure beef. Where as on sample 5 adjacent to the beef fat but are on a regional score of dogs, so the plot it was possible that the suspected market sausage contains a mixture of beef and dog meats. So further research is needed to prove the truth of the existence of a mixture of beef and dog meats on the market samples. 


\section{CONCLUSION}

Spectophotometry FTIR combined with chemometric Partial Least Square (PLS) was found in wave number area 1124-688 $\mathrm{cm}^{-1}$. Calibration model with value $\mathrm{R}^{2} 0.9999$; and RMSEC $0.30 \%$. The results of validation model were obtained from RMSEP value $0.5 \%$; and RMSECV value $0.05 \%$. PCA multivariate analysis could classified beef and dog fat sausages. The analysis results of sausage samples shows that in the market there is one sample that contain dog meat.

\section{REFERENCES}

Che Man, Y.B., Syahariza, Z.A., Mirghani, M.E.S., Jinap, S., and Bakar, J., 2005, Analysis of potential lard adulteration in chocolate and chocolate products using Fourier transform infrared spectroscopy, Food Chemistry. 2005; 90:815-9.

Guntarti, A., Martono, S., Yuswanto, A., Rohman, A., 2015, FTIR Spectroscopy in combination with chemometrics for analysis of wild boar meat in meatball formulation, Asian Journal of Biocemistry, 10(4):165-72.

Gustiani, E., 2009, Pengendalian cemaran mikroba pada bahan pangan asal ternak (daging dan susu) mulai dari peternakan sampai dihidangkan, J. Litbang Pertanian, 28(3) : 96-100.

Jaswir, I., Saeed, M.E., Torla, H. and Zaki, M., 2003, Determination of lard in mixture of body fats of mutton and cow by Fourier Transform Infrared Spectroscopy, J. Oleo Sci.; 52(12): 633-8.

Kusnandar, Feri., 2010, Kimia Pangan Komponen Makro, Dian Rakyat, Jakarta.

Miller, J.N., and Miller, J.C., 2010, Statistics and Chemometrics for Analytical Chemistry, $6^{\text {th }}$ Edition, Pearson Education Limited, Harlow.

Munawaroh, S., Prima, A.H., 2010, Ekstraksi minyak daun jeruk purut (Citrus hystrix D.C.) dengan pelarut etanol dan n-hexane, Jurnal Kompetensi Teknik, 2(1): 73-78.

Mursyidi, A., 2013, The role of chemical analysis in the halal authentication of food and pharmaceutical products, J. Food Pharm. Sci., 1:76-86.

Rahul, B., Radhika, B., Sagar, M.K., Saini, V., Bhat, K., Simultaneous, 2012, Determination of verapamil hydrochloride and gliclazide in synthetic binary mixture and combined tablet preparation by chemometric-assisted spectroscopy, Journal of Analytical Sciences, Methods and Instrumentation, 2:161-166.

Ratnasari, I.U., 2016, Analisis kandungan lemak anjing dalam bakso yang beredar di pasar Wage Purwokerto Menggunakan Fourier Transform Infrared (FTIR) yang dikombinasi dengan kemometrik sebagai autentikasi halal, Thesis, Fakultas Farmasi Universitas Muhammadiyah Purwokerto.

Rafi, M., Anggundari, W.C., Irawadi, T.T., 2016, Potensi spektroskopi FTIR-ATR and kemometrik untuk membedakan rambut babi, kambing, and sapi, Indo. J. Chem. Sci., 5(3):229- 34.

Rohman, A., Kurniawati, E., dan Triyana, K., 2014, Analysis of lard in meatball broth using Fourier transform infrared spectroscopy and chemometrics, Meat Science, 94: 94-98.

Rohman, A., Triyana, K., Sismindari, Erwanto, Y., 2012, Differentiation of lard and other animal fats based on triacylglycerols composition and principal component analysis, International Food Research Journal, 19(2): 475-9.

Rohman, A., Erwanto, Y., Man, Y.B.C., 2011, Analysis of pork adulteration in beef meatball using Fourier transform infrared (FTIR) spectroscopy, Meat Science, 88:91-95.

Ronggo, Y., Chalus, P., Maurer, L., Lema-Martinez, C., Edmond, A., Jent, N, 2007, A Review of Near Infrared spectroscopy and Chemometrics in Pharmaceutical Technologies, Journal of Pharmaceutical and Biomedical Analysis, 44 : 683-700.

Sukirman, E., 2016, Daging Anjing Diolah Menjadi Makanan di Bandung Raya, Accessed on March $2^{\text {th }}, 2017$. 
Syahariza, Z.A., Man, Y.B.C., 2005, Selamat J, Bakar J. Detection of lard adulteration in cake formulation by Fourier transform infrared (FTIR) spectroscopy, Food Chemistry,92:365-371. 